\title{
The Impact of Restrictive Measures on the Price Discovery Function of Stock Index Futures - Evidence From CSI 500 Stock Index Futures
}

\author{
Maoguo $\mathrm{Wu}^{1} \&$ Zhehao Zhu ${ }^{1}$ \\ ${ }^{1}$ SHU-UTS SILC Business School, Shanghai University, Shanghai, China \\ Correspondence: Zhehao Zhu, SHU-UTS SILC Business School, Shanghai University, 20 Chengzhong Road, \\ Jiading District, Shanghai 201899, China.
}

Received: September 25, 2018

doi:10.5430/ijfr.v9n4p117
Accepted: October 10, $2018 \quad$ Online Published: October 11, 2018

URL: https://doi.org/10.5430/ijfr.v9n4p117

\begin{abstract}
Restrictive measures implemented by governments have a great impact on the price discovery function of stock index futures. This study compares the price discovery function of CSI 500 stock index futures and CSI 500 stock index before and after the implementation of restrictive measures based on the reaction speed to new information, the price ratio of new information and the price contribution of both future market and spot market. It also analyzes the difference between the price discovery function of the future market and that of the spot market and thus proposes policy implications accordingly.

Utilizing data of CSI 500 stock index futures in the period of the stock market crash, this study compares the price discovery function before and after the implementation of restrictive measures. By means of the VECM model and common factor analysis, it further investigates the difference in the price contribution of the two markets. Contributing to existing literature on the relationship between the future market and the spot market, this study explores the change in the price contribution of the two markets and therein studies the impact of restrictive measures on the price discovery function. Empirical evidence finds that before the implementation of restrictive measures, the price discovery function worked more efficiently, while, however, after the implementation of restrictive measures, the price discovery function did not work. Hence, stock index futures do assist in the price discovery of the spot market. In some special time periods, however, due to the impact of restrictive policies, the price contribution of the spot market exceeded that of the future market, implying that the price discovery function of the CSI 500 stock index future market is unstable.
\end{abstract}

Keywords: VECM model, common factor analysis, CSI 500 stock index futures, price discovery

\section{Introduction}

June 12, 2015 is a turning point in the Chinese stock market. After reaching the highest point in the history at 5,178, the Shanghai Stock Exchange Composite Index fell by 2,328 points within the following two months. This stock market crash not only caused enormous losses for investors, but also struck China's real economy as it ceased IPO and distorted financing channels, which, in turn, exacerbated the slowing down of China's economic growth. However, this is not the first time that the Chinese stock market has experienced such ups and downs. Since 1990, China has gone through nine such stock market crashes, which is far more than any other countries have endured. In order to mitigate excessive stock market volatility as well as to remedy inefficient pricing, the China Securities Regulatory Commission launched the Shanghai Shenzhen 300 Stock Index (Hushen 300) Futures in April of 2010. This kind of future was expected to stabilize China's stock market and improve pricing efficiency through its price discovery function.

Nevertheless, after Hushen 300 futures and CSI 500 futures were launched, the corresponding spot markets both experienced a tremendous drop, especially with the launch of CSI 500 futures in 2015, by which time the stock market crash was to follow within only 2 months. During this crash, every decrease in the spot market was led by a decrease in the futures market. Although CSI 500 futures represent the overall situation of small and medium-sized enterprises, they are still typical in the market. This indicates that CSI 500 futures could easily be manipulated in the short term due to the small scale of enterprises comprising CSI 500 futures, which is, in turn, likely to cause a stock market crash. 
Based on such a situation, on July 3 and September 7, restrictive measures on stock index futures were implemented in the form of commission fees, a security deposit and transaction volume, which reduced the amount of transaction immediately. With the function of hedging and price discovery, the stock index futures have become an indispensable financial instrument in the global financial market. As a result, policy regarding stock index futures deserve special treatment. In China, however, laws and regulations regarding stock index futures remain immature. In addition, complications in investing and transaction institutions are prevalent. Such issues even regularly bring about sharp drops in the Chinese stock market. As such, this study attempts to analyze the impact of restrictive measures on the price discovery function of stock index futures. In addition, this study compares the effect of CSI 500 stock futures on the price of the spot market before and after the implementation of restrictive measures, so as to figure out whether restrictive measures could make for a more stable spot market. This would help explore the relationship between the stock index futures market and the spot market and lead them to a path of steady and sustainable development.

With September 7 being the cut-off point for implementing restrictive measures, this study utilizes the VECM model to analyze the price-guiding relationship between the CSI 500 index and the high-frequency data of the matching futures. This study further investigates the reaction speed to new information of the futures market and the spot market. On the basis of the VECM model, the data are processed to verify the advantages of the price discovery function of the futures market and the spot market, respectively. This process is achieved via common factor analysis, which utilizes the 'permanent transitory' model and 'information share' model. Furthermore, through impulse response and variance decomposition, this study also examines the different price contributions of the futures market and the spot market. Using these models, this study investigates the change in the price discovery function of the futures market in comparison with that of the spot market after the implementation of restrictive measures. Policy implications are proposed accordingly.

The remaining part of this study is organized as follows. Section 2 reviews related literature. Section 3 introduces the data. Section 4 is devoted to empirical analysis. Section 5 proposes policy implications. Section 6 then concludes.

\section{Related Literature}

Previous literature generally analyzes the price discovery function of stock index futures from the following three aspects: the price-guiding relationship between the futures market and the spot market, the volatility spillover effect of the futures market, and the difference in price contribution of these two markets.

Garbade and Silber (1983) first analyze the leading and lagging relationship between the stock index futures market and the spot market through the dynamic model. Based on this, Kawaller and Koch (1987) find that the price of the futures market is 20-45 minutes ahead of that of the spot market and guides its price. Through the analysis of the time series, Stoll and Whaley (1990) figure out that after controlling price lag and bid-ask spread, the futures market proves to be ahead of the spot market and the time difference could be as much as 10 minutes. Based on the NYMEX oil spot goods and oil futures over 3 months, Wang and Zhang (2005) employ the VECM model and find that the price of oil futures has an obvious guiding role on that of oil spot goods. Likewise, Xiao (2006) points out that the price fluctuation of the futures market could lead to price changes in the spot market and such effects become more obvious when the market grows more mature. Chen (2014) reaches a similar conclusion that the futures market would guide the price of the spot market by analyzing Hushen 300 futures through the VAR model and Granger causality test.

Previous research also studies the volatility spillover effect of various markets. Chan (1991) utilizes the multivariable EGARCH model to analyze the volatility spillover effect of the S\&P 500 index and its futures. It is concluded that the volatility spillover effects of these two markets have a strong two-way influence on each other. Hamilton and Susmel (1994) find that volatility spillover effects can be observed both on high volatility and low volatility by making use of random processes. Koutmos and Tucker (1996) argue that both the future market and spot market have a volatility spillover effect, but the influence of the futures market on the spot market is stronger with a more significant price discovery function. Tse et al., (1999) utilizes the VECM model to analyze the Dow-Jones Average index and its futures. The finding is that the volatility spillover effect mainly occurs in the futures market, which implies that the spot market has a weak impact on the futures market and they both demonstrate obvious asymmetry. In addition, Yan (2009) states that the spot market has a greater impact on the futures market through analysis of the simulation data. However, as simulation data represents high uncertainty, the result is not convincing. Xing (2011) studies the Hushen 300 index as well as its futures and points out that they are affected more by themselves than by each other. Yang (2015) concludes that the price discovery function of the futures market is more significant than that of the spot market and they have an interrelationship with each other in the long run. 
Moreover, a great deal of previous literature pertains to the difference in the price contribution of the futures market and the spot market. Hasbrouck (1995) defines price discovery as a contribution that the market information has made to communalities and thus establishes the Information Share model. Gonzalo and Granger (1995) study the impact of permanent shock and transitory shock on the market price and the contribution of the market to communalities, which is known as the Permanent Transitory model. Chu, Hsieh and Tse (1999) analyze S\&P 500 index and its futures and SPDRs via co-integration analysis and the maximum likelihood estimate method. The result is that price contribution of the futures market is the highest, whereas that of the spot market is the lowest. Ryoo and Smith (2004) find that transaction in the futures market accelerates the speed of receiving and transferring information in the spot market as they study the speed of information transmission using Korea's KOSPI 200 index and its futures. Additionally, Hua and Liu (2010) adopt the VECM model and price discovery model to analyze the high frequency data of Hushen 300 futures. It argues that the futures market dominates price discovery and the price shock of the futures market towards the spot market is rapid and persistent. For their part, moreover, He, Zhang and Chen (2011) find that when deviation between the price of futures and spot goods occurs, the price of the spot market adjusts towards that of the future market. Through the I-S and P-T models, furthermore, they also conclude that the ratio of price contribution of the futures market is high, indicating its leading role in price discovery.

Initial research on the price discovery function of stock index futures mostly adopted the VAR and multivariable GARCH models. The I-S and P-T models then subsequently became the most popular instruments in related research. In addition, the Dow-Jones Average index and the S\&P 500 index could be regarded as mature indices. Some previous research, however, utilizes simulation data, which produces large errors as investors' minds and behavior are unpredictable. In the aspect of sample selection, previous research usually collect data from a relatively stable marketplace or else compare the data of two different markets, in which case, only some general conclusions can be reached that could only be applied to mature markets and/or common situations, but which fail to predict markets with high volatility. Hence, these conclusions achieved through stationary data may not enable investors to hedge or transfer risks.

With the increasing importance of financial derivatives, establishing a stock index futures market with a small mechanism in China is crucial to its unstable and unilateral market, which could also make a great contribution to the understanding of price discovery of stock index futures. Based on previous literature, this study investigates the price-leading relationship between the futures market and the spot market by utilizing the VECM model. Moreover, this study analyzes price contribution via the Information Share model. Furthermore, based on previous research, data from the turbulent time period is analyzed to predict the impact on the price discovery function of stock index futures, especially in an unstable market, which would serve to help investors realize their ultimate goal of hedging rather than providing general advice. Finally, this study investigates whether stock index futures could still play the role of price discovery under restrictive measures and proposes policy implications accordingly.

\section{Data}

This study gathers 5-minute high frequency data from the CSI 500 index and CSI 500 futures from April 17, 2015 to December 31, 2015. High frequency data are used so that a more general conclusion could be reached through the analysis of a big sample. This study selects transaction data in 5 minutes rather than 1 minute on account of the two following reasons. First, Mykland et al., (2005) state that data of higher frequency usually features more market structure noise meaning that 5-minute high frequency data feature less noise than 1-minute data and cause a smaller deviation. When the frequency of the data is higher, however, the more likely is the price to lose time effectiveness, which would amplify the variance of regression analysis. All of the reasons imply that the 5-minute high frequency data make for a more appropriate sample.

In data processing, the CSI 500 stock index is regarded as the spot market price, while the price of CSI 500 stock index futures is regarded as the futures market price. Since the price of the futures is discrete, a continuous sequence is established for further analysis.

As CFFEX released restrictive measures regarding the transaction volume on September 7th, this paper therefore defines the data from April 17 to September 2 as the first group (before implementing restrictive measures) and defines the data from September 7 to December 31 as the second group (after implementing restrictive measures). The data are analyzed in each group and then compared across groups to find out the impact of restrictive measures.

Figure 1 and Figure 2 are the charts of the $1^{\text {st }}$ group and the $2^{\text {nd }}$ group, respectively. From the graphs, it can be seen that the trends of the CSI 500 index and the futures prices are basically the same. However, the amplitude of the $2^{\text {nd }}$ group is relatively larger, with the CSI index obviously being higher than the futures price. 


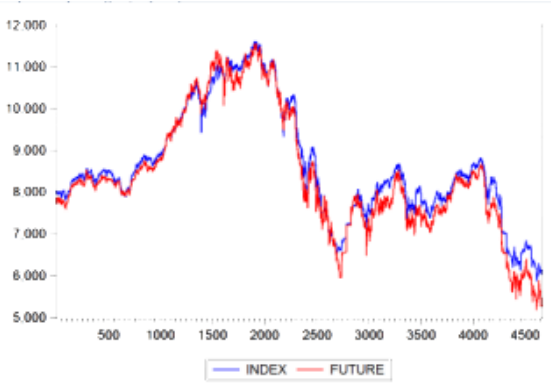

Figure 1. The $1^{\text {st }}$ group

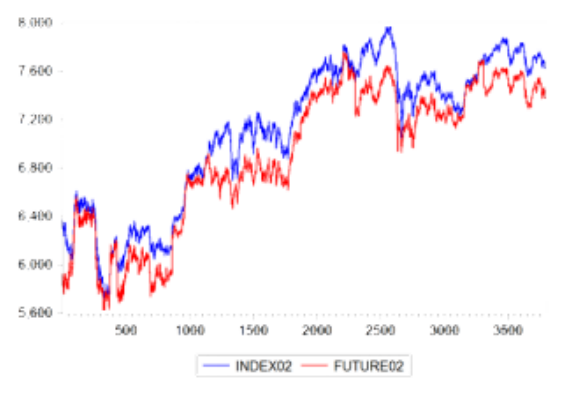

Figure 2. The $2^{\text {nd }}$ group

Table 1 and Table 2 provide descriptive statistics of the $1^{\text {st }}$ group and the $2^{\text {nd }}$ group respectively. The table clearly demonstrates that the statistics of the two markets are very similar. In the first group, the CSI 500 index rises to its peak at 9:40 June, 15, 2015, while the CSI 500 future reaches the peak at 14:05 June, 12, 2015, which are two adjacent transaction dates. Due to the restrictive measures implemented by CFFEX, in comparison with the first group, the degree of fitting of the statistics of the two markets is lower. In the second group, the CSI 500 index reaches its maximum value at 13:25 November 26, 2015, while the CSI 500 future rises to the top at 9:40, November 17, 2015, which has an interval of 7 days. Judging from standard deviations, the volatility of the two markets are basically the same. Nevertheless, in the first group, the volatility of the futures price is higher than that of the index, whereas the statistics of the $2^{\text {nd }}$ group show the opposite result. Furthermore, the skewness and kurtosis of the two groups are different, which turns from right-skewed to left-skewed, certifying the impact of restrictive measures.

Table 1. Basic statistics (the $1^{\text {st }}$ group)

\begin{tabular}{lllllllll}
\hline & Mean & Median & Maximum & Minimum & $\begin{array}{l}\text { Standard } \\
\text { deviation }\end{array}$ & Skewness & Kurtosis & $\begin{array}{l}\text { J-B } \\
\text { Value }\end{array}$ \\
\hline CSI 500 index & 8644.709 & 8383.460 & 11615.98 & 5877.500 & 1345.336 & 0.442203 & 2.489895 & 202.2217 \\
CSI 500 future & 8438.115 & 8213.600 & 11556.80 & 5188.000 & 1473.013 & 0.331188 & 2.476306 & 138.3214 \\
\hline
\end{tabular}

Table 2. Basic statistics (the $2^{\text {nd }}$ group)

\begin{tabular}{lcccccccl}
\hline & Mean & Median & Maximum & Minimum & $\begin{array}{l}\text { Standard } \\
\text { deviation }\end{array}$ & Skewness & Kurtosis & $\begin{array}{l}\text { J-B } \\
\text { Value }\end{array}$ \\
\hline CSI 500 index & 7110.627 & 7284.620 & 7972.720 & 5701.780 & 603.2545 & -0.588189 & 2.033690 & 366.1837 \\
CSI 500 future & 6904.008 & 7071.500 & 7759.800 & 5621.000 & 590.4896 & -0.551252 & 2.011916 & 346.3086 \\
\hline
\end{tabular}

\section{Empirical Analysis}

In order to avoid spurious regression, this study first utilizes the ADF stationarity test and finds that the two series are first-difference stationary, which could satisfy the condition of the co-integration test. After that, the Johansen co-integration test and Granger causality test are applied to find out the relationship between CSI 500 index and CSI 500 future price. The result is that although these two markets may deviate from the equilibrium point in a short period of time, they have a co-integration relationship with each other as well as a long-run equilibrium relationship. Furthermore, based on the 5-minute high frequency data of CSI 500 index and CSI 500 futures, they demonstrate Inter-Granger causality, indicating their price-leading relationship with one another. As a result, this study further utilizes the VECM model for analysis.

In a previous analysis, it is found that raw data of the two groups is not stationary, but the two groups nevertheless have a co-integration relationship, so that the residual of these two groups could be regarded as stationary. In addition, the lagged difference of the first group is 8 , while the lagged difference of the second group is 5 . On the basis of these conditions, this study establishes the VECM model to analyze the leading relationship between the yield rates of the two groups. Since the VECM model is the VAR model with the restriction of co-integration, lags of 
the two groups should subtract 1 , being 7 order and 4 order.

Assume $P_{f, t}=L N F_{t}, P_{i, t}=L N I_{t}, R_{f, t}$ and $R_{i, t}$ are the corresponding first differences. Assume LNF and LNI are the logarithm series of CSI 500 futures price and CSI 500 index respectively. The VECM model is shown as follows:

$$
\begin{gathered}
R_{f, t}=\mu_{f}+\sum_{n-1}^{p} \alpha_{f, n} R_{f, t-n}+\sum_{k-1}^{q} \beta_{f, k} R_{i, t-k}+\gamma_{f}\left(P_{f, t-1}-P_{i, t-1}\right)+\varepsilon_{f, t} \\
R_{i, t}=\mu_{i}+\sum_{n=1}^{p} \alpha_{i, n} R_{i, t-n}+\sum_{k=1}^{q} \beta_{i, k} R_{f, t-k}+\gamma_{i}\left(P_{f, t-1}-P_{i, t-1}\right)+\varepsilon_{i, t}
\end{gathered}
$$

The VECM parameter estimation of the two groups is shown in Table 3 and Table 4:

\begin{tabular}{|c|c|c|}
\hline Error Correction & $\mathrm{D}(\mathrm{DLNF} 01)$ & $\mathrm{D}(\mathrm{DLNI01})$ \\
\hline \multirow[t]{2}{*}{ CoinEq1 } & -0.911308 & 0.578435 \\
\hline & {$[-12.0903]$} & [10.6733] \\
\hline \multirow[t]{2}{*}{ D(DLNF01(-1)) } & -0.114546 & -0.363574 \\
\hline & {$[-1.62625]$} & [-7.17917] \\
\hline \multirow[t]{2}{*}{ D(DLNF01(-2)) } & -0.095737 & -0.264150 \\
\hline & {$[-1.48789]$} & {$[-5.70968]$} \\
\hline \multirow[t]{2}{*}{ D(DLNF01(-3)) } & -0.065263 & -0.212156 \\
\hline & {$[-1.13411]$} & {$[-5.12762]$} \\
\hline \multirow[t]{2}{*}{ D(DLNF01(-4)) } & -0.065849 & -0.181924 \\
\hline & [-1.31333] & {$[-5.04645]$} \\
\hline \multirow[t]{2}{*}{ D(DLNF01(-5)) } & -0.025124 & -0.113697 \\
\hline & {$[-0.59816]$} & {$[-3.76493]$} \\
\hline \multirow[t]{2}{*}{ D(DLNF01(-6)) } & -0.000479 & -0.067888 \\
\hline & {$[-0.01484]$} & {$[-2.92414]$} \\
\hline \multirow[t]{2}{*}{ D(DLNF01(-7)) } & -0.007168 & -0.032118 \\
\hline & {$[-0.35304]$} & {$[-2.20016]$} \\
\hline \multirow[t]{2}{*}{ D(DLNI01(-1)) } & -0.884444 & -0.562576 \\
\hline & {$[-11.5937]$} & {$[-10.2567]$} \\
\hline \multirow[t]{2}{*}{ D(DLNI01(-2)) } & -0.805204 & -0.544172 \\
\hline & [-11.3589] & {$[-10.6768]$} \\
\hline \multirow[t]{2}{*}{ D(DLNI01(-3)) } & -0.717483 & -0.433754 \\
\hline & {$[-11.0122]$} & {$[-9.25929]$} \\
\hline \multirow[t]{2}{*}{ D(DLNI01(-4)) } & -0.560827 & -0.344601 \\
\hline & {$[-9.53364]$} & {$[-8.14741]$} \\
\hline \multirow[t]{2}{*}{ D(DLNI01(-5)) } & -0.457025 & -0.280489 \\
\hline & {$[-8.93341]$} & {$[-7.62546]$} \\
\hline \multirow[t]{2}{*}{ D(DLNI01(-6)) } & -0.313429 & -0.181305 \\
\hline & {$[-7.67633]$} & {$[-6.17588]$} \\
\hline \multirow[t]{2}{*}{ D(DLNI01(-7)) } & -0.126269 & -0.076502 \\
\hline & {$[-4.80155]$} & {$[-4.04602]$} \\
\hline \multirow[t]{2}{*}{$\mathrm{C}$} & $3.22 \mathrm{E}-06$ & $-1.01 \mathrm{E}-06$ \\
\hline & [ 0.02943$]$ & {$[-0.01277]$} \\
\hline
\end{tabular}

Table 3. VECM parameter estimation (the 1st group) 
Table 4. VECM parameter estimation (the $2^{\text {nd }}$ group)

\begin{tabular}{lll}
\hline Error Correction & D(DLNF02) & D(DLNI02) \\
\hline CoinEq1 & -0.330285 & 0.899538 \\
& {$[-5.12407]$} & {$[16.9932]$} \\
D(DLNF02(-1)) & -0.515789 & -0.553233 \\
& {$[-8.88420]$} & {$[-11.6033]$} \\
D(DLNF02(-2)) & -0.381746 & -0.343945 \\
& {$[-7.72021]$} & {$[-8.46978]$} \\
D(DLNF02(-3)) & -0.282739 & -0.240533 \\
& {$[-7.34727]$} & {$[-7.61101]$} \\
D(DLNF02(-4)) & -0.155908 & -0.112211 \\
& {$[-6.29379]$} & {$[-5.51578]$} \\
D(DLNI02(-1)) & -0.366689 & -0.083473 \\
& {$[-4.92235]$} & {$[-1.36442]$} \\
D(DLNI02(-2)) & -0.293184 & -0.104366 \\
& {$[-4.71025]$} & {$[-2.04170]$} \\
D(DLNI02(-3)) & -0.237861 & -0.101874 \\
& {$[-4.99939]$} & {$[-2.60726]$} \\
D(DLNI02(-4)) & -0.075260 & -0.054567 \\
& {$[-2.59020]$} & {$[-2.28679]$} \\
C & $-2.87 \mathrm{E}-06$ & $-1.92 \mathrm{E}-06$ \\
& {$[-0.04555]$} & {$[-0.03705]$} \\
\hline & & \\
& &
\end{tabular}

In Table 3 and Table 4, under the significance level of 5\% and 1\%, most statistics are significant, demonstrating a bi-directional leading relationship between the CSI 500 index and CSI 500 futures. In the equation of the spot, in the $1^{\text {st }}$ group, the lag coefficients of the indices are all significant under the significance level of $1 \%$, indicating that the spot market has mean reversion and is very likely to revert to the mean price. The parameters of the second group also show the same outcome, but less significant than that of the first group. Moreover, the lag coefficients of the futures in both groups do not equal zero, verifying that it is the price in the futures market that leads the price in the spot market.

In the equation of the futures, the lag coefficients of the $1^{\text {st }}$ group are not significant under the significance level of $1 \%$, but significant under the significance level of $5 \%$, which means that the mean reversion of the futures market is not as significant as that of the spot market in the $1^{\text {st }}$ group. In contrast, in the $2^{\text {nd }}$ group, the lag coefficients are significant under the significance level of $1 \%$, so its mean reversion has a stronger effect. The lag coefficients of the spot in the two groups, furthermore, do not equal zero, which implies that the price in the spot market leads the price in the futures market.

Through VECM model, it can also be observed that the CSI 500 index and the CSI 500 future have mutual leading relationships with a long-term equilibrium in both time periods.

This study further explores the relationship between the futures market and the spot market via impulse response analysis. The impulse response analysis is shown in Figure 3 and Figure 4. 


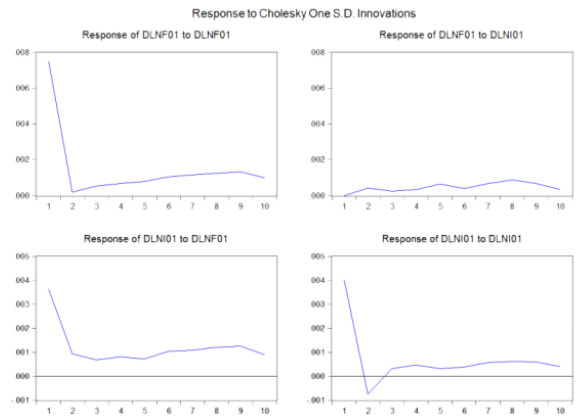

Figure 3 . The $1^{\text {st }}$ group

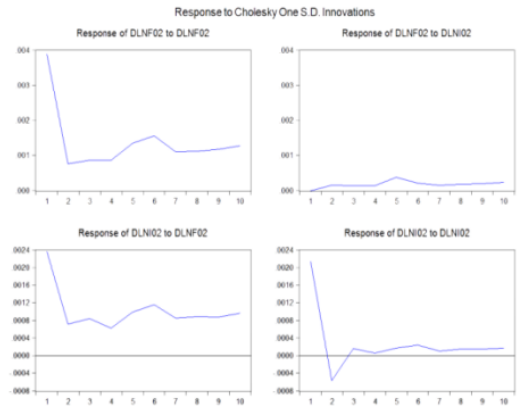

Figure 4. The $2^{\text {nd }}$ group

It can be seen in Figure 3 that in the $1^{\text {st }}$ group, the response of the futures market to its own shock is extremely rapid as it reacts to the shock in the first period and stabilizes afterwards. In contrast, the futures market responds to the shock of the spot market slowly, as it fluctuates repeatedly with small effect. In addition, the spot market responds to the shock of both the spot market itself and the futures market immediately in the first period and then follows a stable pattern thereafter.

In Figure 4, similar to the $1^{\text {st }}$ group, the futures market is not sensitive to the shock from the spot market, but responds rapidly to the shock itself. Additionally, the spot market responds quickly to the shock of the futures market as well as to the spot market itself.

Hence, in two time periods, the price of the futures and the price of the spot have a bi-directional dynamic effect. However, when a shock occurs, the impact of the futures market on the spot market is somewhat larger and faster, while the impact of the spot market on the futures market is not so obvious. As such, the futures market is more sensitive to new information and responds more rapidly. In addition, regarding the time of absorbing new information, the futures market is ahead of the spot market. By comparing the two impulse response diagrams, moreover, the response in the $2^{\text {nd }}$ group is slower and less obvious in comparison with the $1^{\text {st }}$ group, which could be explained by the restrictive measures implemented.

This study utilizes the IS model and PT model to analyze the price contribution of the CSI 500 index market and the CSI 500 futures market. Baillie (2002) argues, moreover, that the IS model is further optimized and connected to the PT model. This study investigates the price discovery function quantitatively by analyzing the upper limit and the lower limit of the IS model and the price contribution of the PT model. The results are shown in Table 5 and Table 6.

Table 5. Price contribution (the $1^{\text {st }}$ group)

\begin{tabular}{lll}
\hline & CSI 500 Future & CSI 500 Index \\
\hline I-S Model & & \\
IS Upper limit & 0.5504438 & 0.4654701 \\
IS Lower limit & 0.5345299 & 0.4495562 \\
Mean & 0.5415431 & 0.4584569 \\
P-T Model & & \\
PT Contribution & 0.5444109 & 0.4155891 \\
\hline
\end{tabular}

Table 6. Price contribution (the $2^{\text {nd }}$ group)

\begin{tabular}{lll}
\hline & CSI 500 Future & CSI 500 Index \\
\hline I-S Model & & \\
IS Upper limit & 0.3006705 & 0.7324648 \\
IS Lower limit & 0.2657843 & 0.6993295 \\
Mean & 0.2861376 & 0.7138624 \\
P-T Model & & \\
PT Contribution & 0.3426752 & 0.6573248 \\
\hline
\end{tabular}


Table 5 shows that in the $1^{\text {st }}$ group, the upper limit and the lower limit of the statistics are very close, so the mean value is calculated for inference. In the IS model, the price contribution of CSI 500 futures is $54 \%$, while that of CSI 500 index is $46 \%$. In the PT model, the result is $58 \%$ and $42 \%$, respectively. This means that in the first group, the price contribution of the futures market is higher than that of the spot market, demonstrating the price discovery function of the futures market.

As can be seen in Table 6 in the $2^{\text {nd }}$ group, the price discovery function of CSI 500 futures is $29 \%$ and that of the CSI 500 index is $71 \%$. In the PT model, the number is $35 \%$ and $65 \%$, respectively. These two models lead to the same result that the price contribution of the futures market is lower than that of the spot market, meaning that the price discovery function of the futures market loses efficacy.

\section{Policy Implications}

Adequate regulations on the newly-developed futures market in China are currently lacking, which could explain why restrictive measures were implemented in 2015 and then resulted in abnormal fluctuations in the market. Hence, China would have to pose harsher censorship on the futures market by establishing more related regulations in order to help this market develop more steadily. In addition, since this market is not mature, new information could not be transmitted to investors promptly and even insider dealing could occasionally occur, which would cause great losses to investors. It follows, then, that establishing a sophisticated information disclosure system could not only enable investors to receive timely information, but also avoid illegal manipulation behavior.

In addition, the futures market in China currently features several built-in constraints on investors. For example, investors are required to have a capital of at least 500 thousand yuan and have relevant investment experience. These requirements prevent many dealers with a small amount of capital from entering the market and also decreases the liquidity of the futures market. In the future, therefore, if China relaxed these requirements and allowed more investors to get involved, the futures market and the financial market could be improved.

Since investors in China's financial market consists of professional investors, institutional investors, and individual investors, some of these investors enter the futures market so as to hedge risks and reduce their possible losses. However, some investors use the futures for speculation instead of hedging in order to earn extra profits, which does not however coincide with the original intention of the market. They are thus likely to suffer huge losses. Accordingly, China should work to help improve dealers' level of professional skills and therein improve the financial market.

\section{Conclusion}

This study investigates the price discovery function of the CSI 500 futures and the CSI 500 index in the stock market crash of 2015 and analyzes the data before and after the restrictive measures. By comparing the two groups of data, the CSI 500 futures market has the function of price discovery before restrictive measures. The bull market was from April to June, during which a large amount of new information and capital entered the stock market and the futures market. Due to the low cost and high transaction speed, many investors -especially institutional investors -entered this market and, as a result, the futures market became able to respond to the new information more quickly. Due to the depressed stock market of June to September, the futures market and the stock market decreased in terms of transaction volume and sensitivity to new information. However, compared to the plunge in the stock market, the futures market only decreased slightly in terms of transaction volume, which is the reason why the CSI 500 futures have the function of price discovery before restrictive measures. CSI 500 futures nevertheless did not retain the price discovery function after restrictive measures. This is because the restrictive measures implemented by CFFEX increased the reserve fund and decreased the transaction volume. Such policies resulted directly in the reduction of transaction volume and, in consequence, many institutions started investing less in the futures market. Due to the decrease in the transaction amount and transaction capital, the futures market would absorb new information much more slowly and hence lose the function of price discovery.

In addition, this study contributes to existing literature on the function of price discovery. While previous research mainly investigates index of mature financial markets like Dow-Jones Average index and S\&P 500 index, this study focuses on HS300 index because of its exceptional volatility and uncertainty. This study provides empirical evidence on the impact of restrictive measures on the function of price discovery for emerging markets and investors in developing countries, especially China. Besides, this study tests the function of price discovery during a period of stock market crash, in which restrictive measures were implemented. As such, investors could make good use of hedging strategies when the stock market experiences volatile fluctuation, and policy makers can resort to implementing restrictive measures to restrain speculation. 
Overall, the stock index futures have the price discovery function. Yet, because of restrictive measures, the price contribution of the spot market would exceed that of the futures market, which reveals that the price discovery function of CSI 500 futures is not stable.

\section{References}

Chan, K., Chan, K., \& Karolyi, G. (1991). Intraday volatility in the stock index and stock futures markets. Review of Finance Studies, 4. https://doi.org/10.1093/rfs/4.4.657

Chen, Q., \& Chen, B. (2015). A Study of the Lead-lag Relationship Between Share Index Futures and Spot. On Economic Problems.

Chu, Q. C., Hsieh, W. G., \& Tse, Y. (1999). Price discovery on the S\&P 500 index markets: An analysis of spot index, index futures, and SPDRs. International Review of Financial Analysis, 8(1), 21-34. https://doi.org/10.1016/S1057-5219(99)00003-4

Garbade, K. D., \& Silber, W. L. (1983). Price movement and price discovery in futures and cash markets. Review of Economics and Statistics, 65, 289-297. https://doi.org/10.2307/1924495

Gonzalo, J., \& Granger, C. W. J. (1995). Estimation of Common Long-memory Components in Co-integrated Systems, Journal of Business \& Economic Statistics, 13, 27-35.

Hamilton, J. D., \& Susmel, R. (1994). Autoregressive Conditional Heteroskedasticity and Regime Changes. Journal of Econometrics, 64(1-2), 307-333. https://doi.org/10.1016/0304-4076(94)90067-1

Hasbrouck, J. (1995). One Security, Many Markets: Determining the Contributions to Price Discovery. Journal of Finance, 50, 1175-1199. https://doi.org/10.1111/j.1540-6261.1995.tb04054.x

He, C., Zhang, L., \& Chen, W. (2011). A study on the price discovery function of HS300 stock index based on high-frequency data. Research on quantitative economics and technical economics, 2805, 139-151.

Holbrook, W. (1962). New Concepts Concerning Futures Markets and Prices. The American Economic Review, 52 , 431-459.

Hua, R., \& Liu, Q. (2010). The Research on Price Discovery Ability Between the Stock Index Futures Market and the Stock Index Spot Market. The Journal of Quantitative \& Technical Economics, 10, 90-100.

Kawaller, I. G., Koch, P. D., \& Koch, T. W. (1987). The temporal price relationship between S\&P 500 futures and the S\&P 500 index. Journal of Finance, 42. https://doi.org/10.1111/j.1540-6261.1987.tb04368.x

Koutmos, G., \& Tucker, M. (1996). Temporal Relationships and Dynamic Interactions between Spot and Futures $\begin{array}{llllll}\text { Stock } & \text { Markets. Journal of }\end{array}$ https://doi.org/10.1002/(SICI)1096-9934(199602)16:1<55::AID-FUT3>3.0.CO;2-G

Ryoo, H. J., \& Smith. G. (2004). The impact of stock index futures on the Korean stock market. Applied Financial Economics, 14(4), 243-251. https://doi.org/10.1080/0960310042000201183

Stoll, H. R., \& Whaley, R. E. (1990). The Dynamics of Stock Index and Stock Index Futures Returns. Journal of Financial and Quantitative Analysis, 25(4), 441-468. https://doi.org/10.2307/2331010

Xiao, H., Bao, J., \& Wu, C. (2006). Study on price discovery process between stock index and stock index futures. Journal of Systems Engineering, 4, 438-441.

Xing, J., Zhou, W., \& Ji, F. (2011). The study of the information transmission and volatility spillover between the HS300 index futures market and the spot market. Securities Market Herald, No.22302, 13-19.

Yan, M., Ba, S., \& Wu, B. (2009). Price Discovery and Volatility Spillovers of Stock Index Futures Markets in China. Systems Engineering, 27(10), 32-38.

Yang, X. (2015). Price discovery and risk spillover effect between stock index future and stock index - empirical research based on HS300 index future 5-min data. Journal of Shandong University (Philosophy and Social Sciences), No.21306, 102-110.

Zhang, X., \& Wang, Q. (2005). The price discovery function of China's listed companies in NYSE-Based on empirical analysis of IS-PT model. Inquiry into Economic Problems, 6, 80-84. 